\title{
Matemática e realidade: uma análise de possibilidades para minimizar dificuldades de aprendizagem
}

\author{
Mathematics and reality: an analysis of possibilities to reduce learning difficulties
}

\author{
Isabel Cristina Machado de Lara* \\ Lanúzia Almeida Brum Avila*
}

\section{Resumo}

Este artigo apresenta uma análise do modo como a utilização da realidade do estudante pode minimizar as dificuldades de aprendizagem (DA) no ensino de Matemática. O objetivo é identificar as percepções dos docentes participantes do estudo acerca da importância da valorização da realidade dos estudantes no processo de aprendizagem, buscando responder a questão central de pesquisa: De que modo abordar a realidade dos estudantes pode minimizar as dificuldades de aprendizagem em Matemática? Para tanto, desenvolveu-se uma pesquisa de abordagem qualitativa. Para realizar a coleta de dados, aplicou-se um questionário com perguntas semiestruturadas a onze docentes de duas escolas, uma pública e a outra privada, dos municípios de Capivari do Sul e Porto Alegre, ambos no Rio Grande do Sul. As respostas foram analisadas por meio da análise textual discursiva (ATD). Conclui-se, com base na análise, que os participantes da pesquisa consideram que abordar a realidade pode minimizar as dificuldades de aprendizagem em Matemática (DAM), desde que o ensino priorize a contextualização e que a linguagem Matemática se aproxime da bagagem cultural trazida pelos estudantes.

Palavras-chave: Contextualização. Dificuldades de aprendizagem em Matemática. Matemática. Realidade.

\section{Abstract}

This paper presents an analysis of the possibility of learning difficulties (DA)- of - be minimized through the use of student reality in the teaching of Mathematics. It aims to identify the perceptions of teachers participating in this study about the importance of valuing the reality of students in the learning process, seeking to answer the central question of this research: How to approach the reality of the students can minimize learning difficulties in mathematics? To this end, it has developed a qualitative research approach. To perform data collection, we applied a questionnaire with semi-structured questions to 11 teachers from two schools, one public and another private municipalities of South Capivari and Porto Alegre. The answers to research questions were analyzed through textual analysis discourse (ATD). The conclusion is based on this analysis that the research subjects consider approaching reality can minimize learning difficulties in mathematics (DAM), since the school prioritizes the context and the mathematical language to approach the cultural baggage brought by the students.

Keywords: Contextualization. Learning difficulties in mathematics. Mathematics. Reality.

Recebido em: 14/01/2017 - Aprovado em: 07/07/2017

http://dx.doi.org/10.5335/rep.v24i2.7419

Mestre e doutora em Educação pela Universidade Federal do Rio Grande do Sul, com pós-doutoramento em Educação em Ciências e Matemática na Pontifícia Universidade Católica do Rio Grande do Sul (PUCRS). Professora permanente no Programa de Pós-Graduação em Educação em Ciências e Matemática e da Faculdade de Matemática da PUCRS. E-mail: isabel.lara@pucrs.br

** Mestre em Educação em Ciências e Matemática (PUCRS). Psicopedagoga Institucional e Clínica (Fapa). Licenciada em Pedagogia - Orientação Educacional (Fapa).E-mail: lanuzia.avila@acad.pucrs.br 


\section{Introdução}

A Matemática é referida por N. Machado (1997) como uma disciplina básica no currículo das escolas e presente desde os anos iniciais da escolarização, em todo o mundo, pelo consenso de sua necessidade no ensino desde o processo da alfabetização. Entretanto, muitos docentes não têm entendimento quanto à utilidade da Matemática e à necessidade de contextualizá-la, vinculando-a à realidade dos estudantes. Além disso, o autor defende a ideia de bem cultural de interesse geral. Entretanto, muitas visões acerca dessa ciência tendem a considerá-la como um universo a parte da realidade. Segundo N. Machado (1997), as superações dos problemas quanto ao ensino da Matemática acontecerão no momento em que houver uma aproximação entre seu significado e a fundamentação do raciocínio entre as ciências.

Conforme Lara (2004), a Matemática é vista pelos estudantes como uma das disciplinas mais difíceis do currículo escolar, e, historicamente, produziu-se o discurso, considerado como verdadeiro para muitos pais e professores, de que são naturais as dificuldades ocorridas nos processos de ensino e aprendizagem, implicando em um ensino inapropriado da Matemática. A autora afirma que, por vezes, muitas dessas dificuldades podem estar relacionadas à falta de contextualização dos conceitos ensinados (LARA, 2004). Desse modo, torna-se relevante a aproximação do significado da Matemática com a realidade em que o sujeito está imerso, a qual se modifica constantemente.

Pensando nisso, realizou-se uma pesquisa de abordagem qualitativa acerca da utilização da realidade do estudante para minimizar suas dificuldades de aprendizagem (DA). O objetivo desta pesquisa é identificar a percepção dos docentes acerca da importância da valorização da realidade dos estudantes no processo de aprendizagem. Para tanto, onze professores responderam um questionário com seis questões, das quais foram selecionadas quatro para análise, as quais atendiam à questão central: "De que modo abordar a realidade dos estudantes pode minimizar as dificuldades de aprendizagem em Matemática?".

Como método de análise, adotou-se a análise textual discursiva (ATD), perfazendo as três etapas definidas por Moraes e Galiazzi (2011): unitarização, categorização e comunicação das novas compreensões atingidas - metatexto.

Nesse sentido, espera-se que, a partir da análise dos enunciados dos sujeitos, seja possível contribuir para que pedagogos e professores de Matemática possam repensar acerca da necessidade de propor um ensino baseado na problematização, na contextualização e na construção do conhecimento, e não na mera transmissão de conteúdos desconectados da realidade dos estudantes. 


\section{Matemática, realidade e dificuldades de aprendizagem: reflexões acerca do ensino}

De acordo com N. Machado (1997), o termo Matemática é de origem grega, tendo como significado "o que se pode aprender". O autor também faz referência às definições encontradas no dicionário Aurélio e na Enciclopédia Britânica:

No dicionário Aurélio, matemática é definida como "ciência que investiga relações entre entidades definidas abstrata e logicamente". Quanto a definição da enciclopédia, a matemática é tida como a "ciência que lida com as relações e simbolismos de números e grandezas e que inclui operações quantitativas e soluções de problemas quantitativos" (MACHADO, N., 1997, p. 7).

Descartes denominou de Matemática Universal a ciência de modo geral, a qual deve abranger os primeiros elementos da razão humana, proporcionando o surgimento de verdades sobre todo e qualquer assunto (MACHADO, N., 1997).

N. Machado (1997) remete ao ensino da Matemática como sendo uma tarefa difícil, e as dificuldades intrínsecas acabam por somar-se à visão distorcida que muitos professores têm a respeito da disciplina. Considerando esses aspectos, o autor menciona que a Matemática "[...] se aplica ao real ou, o que é mais grave, rege-o, somente assim poder-se-ia repensar o ensino da Matemática em um sentido globalizante. Um sentido [...] que possa inscrever tal ensino numa perspectiva de ação transformadora" (MACHADO, N., 1997, p. 17).

Desse modo, N. Machado (1997) ressalta que a Matemática, ainda hoje, é ensinada nas escolas enfatizando a sua linguagem própria. A preocupação centra-se em escrever corretamente, falar corretamente, ao invés de preocupar-se em favorecer o pensar e o criar. $\mathrm{O}$ autor aponta a falta de compreensão quanto à utilidade da Matemática como a possível responsável pelas dificuldades crônicas ocorridas no ensino da disciplina.

Corroborando essa ideia, Lara afirma que: "Há muito tempo, a Matemática traz consigo a imagem de disciplina mais difícil do currículo escolar, efeito disso é considerar normal a presença de dificuldades tanto no processo de ensino como de aprendizagem" (2004, p. 137). Entretanto, a autora afirma que é preciso colocar sob suspeita esse discurso tido como verdade absoluta, pois, se existem dificuldades para o estudante aprender, consequentemente, existem causas para que isso aconteça, em muitos casos, um ensino inapropriado da disciplina, um ensino ultrapassado e descontextualizado da realidade dos estudantes (LARA, 2004).

Ainda conforme Lara, 
[...] o modo como os saberes matemáticos vêm sendo tratados fazem com que a Matemática passe a ser um corpo fechado de saberes verdadeiros, atemporais e irrefutáveis, passível então, de transmissão [...] o aluno constitui-se como um mero receptor e repetidor [...] a maneira como a Matemática aparece em alguns livros didáticos reflete a imagem de um conjunto de conteúdos ou definições hierarquizadas e entrelaçadas (2004, p. 141).

Conforme a Classificação Estatística Internacional de Doenças e Problemas Relacionados à Saúde - CID-10 e o Manual Diagnóstico e Estatístico de Transtornos Mentais - DSM-V, uma diversidade de termos é utilizada para descrever a dificuldade de aprendizagem (DA), sendo, em alguns casos, definida como desordem de aprendizagem ou transtorno de aprendizagem (TA), em que o estudante apresenta dificuldades no aprendizado, o que afeta a capacidade do cérebro em receber e processar as informações, podendo tornar um problema o estudante aprender, se comparado com outro de mesma idade e sem essa dificuldade.

Conforme Relvas (2015), as DA são definidas como “[...] resultado de algumas falhas intrínsecas ou extrínsecas desse processo aprendizagem [...]” (2011, p. 58). Além disso, abrangem "[...] um grupo heterogêneo de problemas capazes de alterar as possibilidades de a criança aprender, independentemente de suas condições neurológicas para fazê-lo" (RELVAS, 2015, p. 58-59).

Complementando essa ideia, Ohlweiler ressalta que:

As dificuldades de aprendizagem podem ser [...] de percurso, causadas por problemas da escola e/ou da família, que nem sempre oferecem condições adequadas para o sucesso da criança [...] dificuldades que a criança pode apresentar em alguma matéria ou em algum momento da vida, além de problemas psicológicos, como falta de motivação e baixa auto-estima (2006, p. 127).

Fernández (2001) corrobora esse pensamento, salientando que muitas crianças no período escolar tendem a apresentar dificuldades na realização das tarefas escolares, podendo, em alguns casos, ser advindas da proposta pedagógica do professor, relativas a questões familiares ou a déficits cognitivos. A autora denomina esses fatores como dificuldades de percurso, decorrentes da falta de condições apropriadas para que a aprendizagem ocorra com êxito.

De acordo com Fonseca,

[...] se torna difícil determinar a natureza precisa das causas endógenas das DA. Envolvimentos familiares pobres, relação criança-adulto distorcidas, expectativas negativas, erros pedagógicos... situações de aprendizagem limitativa, [...] podem também produzir DA (2000, p. 98).

Entretanto, as DA também podem advir de fatores secundários a outros quadros patológicos, bem como: alterações sensoriais, transtornos psiquiátricos, doenças crônicas, doenças neurológicas e deficiência mental, mais frequentemente, a 
paralisia cerebral e o transtorno de déficit de atenção e hiperatividade (TDAH) (RELVAS, 2015).

Referente ao estudo das dificuldades de aprendizagem em Matemática (DAM), García (1998) menciona que teve início há poucas décadas, pois a preocupação principal estava relacionada às habilidades verbais, como a leitura, a qual era valorizada, pelas medidas educativas, mais do que a Matemática. No entanto, García evidencia que a "[...] compreensão das DAM exige conhecer com clareza os processos e passos no desenvolvimento e aprendizagem das habilidades relacionadas com o número e com a matemática nas crianças" (1998, p. 215).

Nem sempre é possível ao professor detectar se a dificuldade é específica de um conteúdo ou de uma disciplina, ou se há dificuldades também em outras disciplinas. Em alguns casos, faz-se necessário o auxílio do setor pedagógico da escola, para buscar informações sobre a história de vida do estudante e, se necessário, chamar os pais para uma reunião, pois é importante ter discernimento se a dificuldade é específica ou se está relacionada a fatores secundários, de modo que o professor possa intervir adequadamente e a aprendizagem venha a acontecer com sucesso (ROTTA, 2006).

Contudo, dependendo da dificuldade, nem sempre o trabalho do professor consegue dar conta, sendo necessário o encaminhamento, por meio do setor pedagógico, aos profissionais especializados, como: psicopedagogo, psicólogo, psiquiatra, neurologista, fonoaudiólogo, para realização de um trabalho multidisciplinar com a escola, a família e o estudante (ROTTA, 2006).

\section{Procedimentos metodológicos}

\section{Método de pesquisa}

Com o objetivo de identificar a percepção dos docentes acerca da importância da valorização da realidade dos estudantes no processo de aprendizagem, neste estudo, foi utilizada como método de pesquisa a abordagem qualitativa.

Fini (1997) define a pesquisa qualitativa como sendo uma das alternativas para conduzir pesquisas na área educacional, tendo como intenção oportunizar ao pesquisador o envolvimento com o ato de sua pesquisa. Nessa perspectiva, sempre haverá um sujeito inserido em um contexto, vivenciando determinada situação.

Em se tratando da coleta de dados, na pesquisa qualitativa, busca-se, de acordo com O. Machado (1997), compreender o fenômeno a ser estudado, a partir da interrogação das experiências dos sujeitos em sua vida cotidiana, isto é, a intenção é compreender as situações vivenciadas pelos sujeitos em seu mundo real. 


\section{Participantes da pesquisa}

$\mathrm{Na}$ intenção de alcançar o objetivo proposto neste estudo, participaram desta pesquisa onze docentes, entre 24 e 46 anos de idade, dos quais, seis com formação inicial em Pedagogia, dois em Matemática e um com mestrado em Educação em Ciências e Matemática, de duas escolas, uma pública e a outra privada, dos municípios de Capivari do Sul e Porto Alegre, RS. Os docentes participantes da pesquisa serão denominados por Professor 1, Professor 2, Professor 3, e assim sucessivamente, com a intenção de manter o seu anonimato.

\section{Instrumento para coleta de dados}

Como instrumento para a coleta dos dados desta pesquisa, optou-se por um questionário semiestruturado, encaminhado por e-mail aos coordenadores pedagógicos das escolas.

Referente à utilização do questionário como instrumento de coleta de dados, Gil (2002) define como um grupo de questões que devem ser respondidas por escrito pelos participantes da pesquisa, sem a presença do pesquisador. De acordo com o autor, o questionário é o um instrumento rápido e de valor acessível para a coleta de dados, propiciando ainda o anonimato dos participantes da pesquisa. Em relação à elaboração do questionário, Gil aponta que "[...] consiste basicamente em traduzir os objetivos específicos da pesquisa em itens bem redigidos. Naturalmente, não existem normas rígidas a respeito da elaboração do questionário" (2002, p. 116).

No estudo em questão, optou-se por utilizar questões semiestruturadas, devido à abordagem de pesquisa qualitativa. Foram utilizadas as questões a seguir:

a) Para você, o que é Matemática?

b) O que é realidade para você?

c) Qual a sua percepção acerca das dificuldades de aprendizagem em Matemática?

d) De que modo você considera que abordar a realidade dos estudantes pode minimizar as dificuldades de aprendizagem em Matemática?

\section{Método de análise}

Como método de análise, utilizou-se a ATD, considerada por Moraes e Galiazzi (2011) como um processo auto-organizado referente à compreensão de novos entendimentos, os quais emergem de três etapas: unitarização, categorização e comunicação das novas compreensões atingidas - metatexto. 
$\mathrm{Na}$ etapa de desmontagem dos textos, também chamada de unitarização, os textos são examinados em detalhes, fragmentando-os em unidades constituintes, ou seja, criando enunciados em relação aos documentos em estudo.

No que diz respeito à segunda etapa, Moraes e Galiazzi (2011) salientam o estabelecimento de relações, também denominado de categorização, em que a meta está centrada na compreensão de como elementos unitários podem vir a ser reunidos, no intento de formar conjuntos mais complexos, ou seja, as categorias. Sendo assim, os autores mencionam que: "A categorização é um processo de comparação constante entre as unidades definidas no momento inicial da análise, levando a agrupamentos de elementos semelhantes. Conjuntos de elementos de significação próximos constituem as categorias" (2011, p. 22).

Durante o processo de categorização, as categorias podem ser construídas em níveis diferenciados, podendo ser denominadas como iniciais, intermediárias e finais, apresentadas como categoriais mais abrangentes e em menor número. Moraes e Galiazzi (2011) enfatizam que as categorias formam os metatextos, os quais o pesquisador tem como pretensão escrever, isto é, produzir as interpretações e novas compreensões possibilitadas por meio da análise.

Em se tratando da captação do novo emergente, conforme Moraes e Galiazzi (2011), é a etapa em que se tem o metatexto como resultado das duas etapas anteriores, com base na descrição e na interpretação dos fenômenos em estudo pelo pesquisador. Segundo os autores, “[...] toda análise textual qualitativa corresponde a um processo reiterativo de escrita em que, gradativamente, atingem-se produções mais qualificadas. [...] a partir da unitarização e categorização constrói-se a estrutura básica do metatexto" (MORAES; GALIAZZI, 2011, p. 32-33).

A última etapa da ATD é denominada por Moraes e Galiazzi (2011) de processo auto-organizado, no qual a intenção é o movimento de desordem em direção à organização de uma nova ordem, ou seja, a partir do caos, a emergência do novo, do processo auto-organizado e intuitivo, resultando, assim, na produção dos metatextos.

Dessa forma, Moraes e Galiazzi evidenciam que "[...] a análise textual discursiva pode ser compreendida como um processo auto-organizado de construção de novos significados em relação a determinados objetos de estudo, a partir de materiais textuais referentes a esses fenômenos" (2011, p. 45).

Os dados desta pesquisa foram organizados em um único arquivo, com suas respectivas codificações. Esse processo perfez as seguintes etapas: desconstrução das respostas dos sujeitos em unidades de significado; análise das unidades de significado; reescrita interpretativa acerca das unidades; agrupamento das unidades conforme similaridades, originando vinte categorias iniciais, as quais foram 
reagrupadas por semelhanças, originando duas categorias finais de análise para cada uma das quatro questões.

Com base nas categorias que emergiram, redigiu-se o metatexto de modo interpretativo, em diálogo entre os autores, os quais contribuíram para a compreensão do conteúdo e do discurso explícito e implícito no corpus de análise e para a construção de respostas ao problema de pesquisa. A seguir, são detalhadas as categorias que emergiram desse processo.

\section{0 que é Matemática}

Esta seção, tem como intuito apresentar a análise de duas categorias que emergiram do processo de ATD acerca das respostas dos docentes participantes desta pesquisa à questão Para você o que é Matemática?: Matemática e dia a dia, Matemática e raciocínio lógico.

\section{Matemática e dia a dia}

Na categoria Matemática e dia a dia (8), ${ }^{1}$ os participantes da pesquisa destacam que a Matemática está presente em nosso dia a dia, desde o momento em que acordamos até a hora de dormir. Nesse sentido, N. Machado refere-se à Matemática como "[...] objeto de cultura, como ferramenta de trabalho, que revele com clareza o quanto [...] está inserida no processo histórico-social onde é produzida e que ela ajuda a produzir" (1997, p. 16-17).

Dessa forma, destaca-se a Matemática como parte do cotidiano e sendo essencial para a vida, conforme refere o Professor 2: "Enxergo a matemática como algo essencial para vida, pois está em tudo ao nosso redor, desde que acordamos, tomamos café até a hora que deitamos, para tudo precisamos dela".

De acordo o Professor 7, a Matemática "[...] é a realidade do dia a dia. Tudo envolve a matemática". Isso vai ao encontro do que N. Machado (1997) afirma, quando enfatiza a necessidade de o conhecimento matemático se relacionar com a realidade, pois é somente a partir desta visão que poderá ser repensado seu ensino, numa perspectiva transformadora.

O Professor 3, em seus apontamentos, menciona que a Matemática: "É a arte de conviver com o mundo. É uma ciência que nos permite compreender o pensamento relacionando com o mundo". Essa ideia também é evidenciada em N. Machado: 
Em todos os lugares do mundo, independente de raças, credos ou sistemas políticos, desde os primeiros anos de escolaridade [...] faz parte dos currículos escolares, ao lado da Linguagem Natural, como uma disciplina básica. Parece haver um consenso com relação ao fato de que seu ensino é indispensável e sem ele é como se a alfabetização não tivesse completado (1997, p. 8).

Assim, a análise evidencia que os participantes da pesquisa definem a Matemática como sendo essencial para a vida, pois está presente em situações diárias, com o papel de possibilitar a compreensão do pensamento e relacioná-lo com o mundo a sua volta.

\section{Matemática e raciocínio lógico}

Em relação à categoria Matemática e raciocínio lógico (5), os participantes da pesquisa definem a Matemática como sendo a ciência do raciocínio lógico, da resolução de problemas e dos números. Isso se relaciona ao que Lara afirma: "Historicamente o ensino da Matemática tem sido visto pelos professores, e de certo modo pela sociedade em geral, como a maneira por excelência de desenvolver o raciocínio do aluno" (2005, p. 11). Tal afirmação é identificada na fala do Professor 6: "É o estudo e o desenvolvimento do raciocínio lógico e da resolução de incógnitas. É a forma de entender e transmitir o conhecimento de números e outros artifícios que envolvem o raciocínio lógico".

Nesse sentido, Lara destaca que:

[...] os professores têm apontado, como objetivo dessa disciplina, o desenvolvimento de habilidades para resolver problemas, o que favoreceria a compreensão do mundo e a formação do pensamento crítico, assegurando o desenvolvimento individual e a integração na sociedade. [...] como se a disciplina de Matemática fosse o meio privilegiado para o desenvolvimento da racionalidade e da inteligência, do pensamento crítico e do desenvolvimento individual e social (2005, p. 11).

Dessa forma, os participantes da pesquisa mencionam que a Matemática ensina a pensar e a refletir. Isso é perceptível na resposta do Professor 9: "[...] raciocínio lógico, exigi do estudante atenção, leitura e uma boa interpretação".

De acordo com Smole, Diniz e Cândido:

Com relação ao trabalho com a matemática a ideia de que há um ambiente a ser criado na sala de aula que se caracterize pela proposição, pela investigação e pela exploração de diferentes situações-problema por parte dos alunos [...] a interação entre os alunos, a socialização de procedimentos encontrados para solucionar uma questão e uma troca de informações são elementos indispensáveis em uma proposta que visa a uma melhor aprendizagem da matemática (2007, p. 13). 
Assim, verifica-se que os participantes da pesquisa percebem que a Matemática tem como objetivo proporcionar o pensamento lógico e reflexivo. Contudo, Lara (2005) aponta que só será possível que o ensino da Matemática propicie o raciocínio lógico, a criatividade e o pensamento quando os professores realizarem com seus estudantes um ensino baseado na realidade, visando à construção do conhecimento.

Com base na análise das categorias, percebe-se que a Matemática é, por um lado, considerada como parte do cotidiano e como essencial no dia a dia, pois se faz presente em tudo o que fazemos, permitindo compreender o mundo, por outro, é definida como a ciência do raciocínio lógico, da resolução de problemas e dos números, possibilitando aos estudantes o pensamento crítico e reflexivo.

0 que é realidade

Esta seção apresenta a análise de duas categorias que emergiram do processo de ATD acerca das respostas dos docentes participantes desta pesquisa para a questão Para você o que é realidade?: cotidiano, realidade e dificuldades de aprendizagem.

\section{Cotidiano}

No que diz respeito à categoria Cotidiano (10), os participantes da pesquisa definem realidade como sendo vivenciar experiências relacionadas ao mundo de forma concreta e com relação ao que se está aprendendo.

De acordo com o Professor 5, realidade é: "Vivenciar experiências relacionadas com o mundo que vivemos, conhecendo o nosso em torno para assim atuarmos como cidadãos". Essa ideia é destacada por N. Machado quando indica que "[...] o conhecimento matemático nasce do real e a ele se dirige como ocorre em todos os outros campos" (1997, p. 58).

Lara defende a ideia de que:

Uma aprendizagem significativa e relevante é fundamental para o processo de aprendizagem do conhecimento matemático [...] é uma das maiores dificuldades encontradas pelo professor, que insiste num ensino obsoleto, descontextualizado e a-histórico (2004, p. 137).

Nas respostas dos sujeitos, é possível perceber a percepção de realidade como algo que acontece no dia a dia, sendo capaz de simplificar o cotidiano e aproximar o que aprendemos do que vivemos. Isso é perceptível na fala do Professor 7, quando especifica que: "Realidade é o que acontece, é o que vivenciamos e vivemos no decorrer da nossa vida". 
Desse modo, os participantes da pesquisa ressaltam a aproximação do significado da Matemática em relação com a realidade do estudante, que se modifica constantemente.

\section{Realidade e dificuldades de aprendizagem}

Apenas um participante relacionou realidade às dificuldades enfrentadas pelos estudantes e à falta de apoio e interesse dos pais em desenvolver um trabalho em parceria com os professores.

Nesse sentido, Lara salienta que:

[...] compreender o desenvolvimento da cognição humana é uma tarefa difícil, porque cada aluno é um sujeito único, com pensamentos e reações únicas. Cada um provém de um contexto cultural distinto, com conhecimentos prévios, atitudes e modos de pensar diversos [...] necessidade de aceitar que compreender como evolui o pensamento e interpretar comportamentos não é trabalho apenas de psicólogos ou psicopedagogos, mas também do professor [...] buscar, pesquisar, na tentativa de perceber como são aprendidos os conceitos matemáticos $(2004$, p. 145).

Em sua resposta, o Professor 9 remeteu as DA como sendo a realidade enfrentada pelos professores no ensino. Isso fica nítido quando especifica em seu enunciado que: "Realidade é o que vivemos hoje com nossos estudantes, as dificuldades apresentadas por eles e que não sinto parceria das famílias".

Lara, ao retratar sua preocupação em repensar o ensino da Matemática, aponta que: "[...] os pressupostos tidos como verdades absolutas que constituíram nossos professores, tanto a respeito da construção do conhecimento como da própria Matemática, que se transforma no real problema da dificuldade de aprendizagem em Matemática" (2005, p. 31).

A percepção desse participante é preocupante, pois sua visão de realidade relacionada às DA em sua prática pedagógica parecem se sobrepor à aprendizagem de seus estudantes, como se as dificuldades enfrentadas fossem mais presentes no cotidiano do que a aprendizagem significativa.

A partir da análise das categorias, observa-se que os sujeitos, em sua maioria, definem realidade como sendo a aproximação entre as vivências relacionadas ao mundo com a aprendizagem e sua importância no ensino da Matemática, pois, de acordo com os professores pesquisados, somente dessa maneira é possível um ensino que priorize a realidade dos estudantes, realidade essa que está em constante transformação. Entretanto, um dos participantes pesquisados definiu realidade como sendo a sua realidade vivenciada em sala de aula, que é, segundo ele, permeada de dificuldades enfrentadas pelos estudantes e falta de apoio dos pais em auxiliar os filhos num trabalho em conjunto com a escola. 


\section{Percepção dos professores acerca das dificuldades de aprendizagem em Matemática}

Esta seção tem como intuito apresentar a análise de duas categorias que emergiram do processo de ATD acerca das respostas dos docentes participantes desta pesquisa à questão Qual a sua percepção acerca das dificuldades de aprendizagem em Matemática?: dificuldades de aprendizagem e descontextualização; causas das dificuldades de aprendizagem.

\section{Dificuldades de aprendizagem e descontextualização}

No que tange à categoria dificuldades de aprendizagem e descontextualização (9), os participantes da pesquisa mencionaram que as dificuldades estão relacionadas à falta de pré-requisitos nos anos iniciais, à forma como o professor transmite os conteúdos e à descontextualização.

Segundo N. Machado: "Ensinar Matemática tem sido, frequentemente, uma tarefa difícil. Às dificuldades intrínsecas, se somam as decorrentes de uma visão distorcida da matéria, estabelecida, muitas vezes, desde os primeiros contatos" (1997, p. 9).

Conforme o Professor 4:

[...] a grande dificuldade na matemática se apresenta nos anos iniciais, que a cada ano se agrava com a abordagem dos conteúdos, principalmente quando se usa a linguagem matemática, falta um olhar, um saber matemático que precisa ser desenvolvido em cada aluno.

Desse modo, N. Machado ressalta que "[...] a Matemática tem sido ensinada em quase todos os níveis com uma ênfase que consideramos exagerada na linguagem matemática" (1997, p. 97). A citação vai ao encontro da resposta do Professor 11, que diz: "Os números e códigos muitas vezes se tornam abstratos para algumas crianças de tal modo que as dificuldades surgem".

Nesse sentido, destaca Lara: "O modo como o professor se expressa, ou seja, se comunica com o estudante em sala de aula pode, se tornar um dos causadores das dificuldades encontradas pelos alunos para aprender Matemática" (2004, p. 138).

Diante disso, observa-se que os participantes atribuíram as questões das dificuldades ao modo como a Matemática é desenvolvida em sala de aula, principalmente se estiver desvinculada do contexto dos estudantes, o que acaba ocasionando desinteresse pela disciplina. 


\section{Causas das dificuldades de aprendizagem}

Na categoria causas das dificuldades de aprendizagem (4), os participantes da pesquisa se referem à visão dos estudantes acerca da disciplina de Matemática, ao desinteresse e ao medo diante dos desafios e das dificuldades relacionadas aos campos cognitivo, emocional e/ou neurológico.

O Professor 2 diz: "Tenho alunos que têm pavor da Matemática e outros que amam, é bem dividida essa questão, mas os que têm dificuldade sempre falam que não vão conseguir fazer determinadas atividades e que nunca vão aprender a tal Matemática". As ideias trazidas por esse sujeito remetem ao que Lara indica: “[...] para aprender o aluno precisa querer aprender [...] o professor precisa perceber como o aluno sente-se motivado, entusiasmado e desafiado, assim como também ele mesmo deve se autoconhecer para agir como um entusiasta em sala de aula" (2005, p. 144).

As variáveis psicológicas são retratadas como uma das causas de DA pelo Professor 5: "[...] alguns traumas durante suas vivências escolares [...]". Isso vai ao encontro da afirmação de Lara: "[...] o modo de subjetivação adotado pelo professor, que obviamente emergirá dos seus pressupostos e de sua própria constituição como docente de Matemática, é responsável muitas vezes pela dificuldade de aprendizagem" (2005, p. 148).

Em relação à aprendizagem, Ohlweiler (2006) acentua o papel que exerce a escola nesse processo, pois a forma com que o docente reconhece o estudante como sujeito da aprendizagem, o espaço que é proporcionado para as perguntas, a estimulação por meio do lúdico, a socialização com os colegas da mesma idade e o modo como o estudante se autoriza como autor de seu processo de autoria de pensamento são aspectos fundamentais para o aprendizado.

Entretanto, de acordo com Rotta (2006), as DA podem ser secundárias a outras patologias: doenças neurológicas, alterações das funções sensoriais, transtornos psiquiátricos, entre outras doenças. Isso é perceptível na resposta do Professor 3: "[...] salvo se o aluno apresentar outras dificuldades no campo psicopedagógico e ou neurológico".

Porém, conforme menciona Rotta (2006), além de DA, pode existir TA para leitura e escrita (dislexia) e para Matemática (discalculia), em que os estudantes apresentam resultados significativamente abaixo do esperado. Uma das questões trazidas pelos participantes da pesquisa foram os TA, o que se verifica no enunciado do Professor 3: "[...] e por apresentarem transtornos da aprendizagem".

Nessa questão, os participantes da pesquisa atribuíram as dificuldades vivenciadas pelos estudantes a uma série de variáveis. Verifica-se, entretanto, que o destaque é dado às influências negativas que o ensino da Matemática pode desencadear na vida do estudante, ocasionando, em alguns casos, aversão à disciplina, por medo do insucesso e do fracasso escolar. 
Referente à análise das duas categorias, percebe-se que as DA, para muitos participantes, estão relacionadas à falta de pré-requisitos e ao modo como o professor transmite os conteúdos, isto é, a linguagem matemática que é utilizada para ensinar, o que ocasiona desinteresse dos estudantes e até mesmo aversão à disciplina. Contudo, outros participantes da pesquisa acreditam que a visão dos estudantes sobre a matemática, o desinteresse, o medo do fracasso e as dificuldades cognitivas e/ou neurológicas são os responsáveis pelas DAM.

\section{Abordar a realidade dos estudantes pode minimizar as dificuldades de aprendizagem em Matemática}

Esta seção apresenta a análise de duas categorias que emergiram do processo de ATD acerca das respostas dos docentes participantes desta pesquisa à questão De que modo você considera que abordar a realidade dos estudantes pode minimizar as dificuldades de aprendizagem em Matemática?: a aprendizagem precisa ser significativa; resolução de problemas e jogos.

\section{A aprendizagem precisa ser significativa}

Em relação à categoria a aprendizagem precisa ser significativa (5), os participantes da pesquisa afirmam que as dificuldades podem ser minimizadas se os conteúdos trabalhados em Matemática estiverem atrelados à realidade dos estudantes, tornando-se, assim, significativo aprender determinado conteúdo.

Segundo Lara (2004), a forma como o docente se expressa ao ministrar suas aulas pode influenciar negativamente e se tornar um dos indícios de DAM para muitos estudantes. Para a autora, é importante o docente ter clareza ao se comunicar com seus estudantes, possibilitando que compreendam o que está sendo ensinado, que possam abstrair determinado assunto e, primordialmente, relacioná-lo com seus conhecimentos.

De acordo com o Professor 7: "[...] abordar os conteúdos vinculando a realidade dos alunos facilita a aprendizagem e o gosto em aprender". A resposta desse participante vai ao encontro das ideias destacadas por Lara quando destaca que: "[...] o aluno já traz para sala de aula uma bagagem cultural rica em conhecimentos matemáticos. Mesmo que não formais ou abstratos esses conhecimentos podem ser nosso ponto de partida para introduzir [...] determinados conteúdos matemáticos” (2005, p. 15).

A necessidade de relacionar os conteúdos matemáticos aos conhecimentos dos estudantes é destacado pelo Professor 5: "[...] no momento que o conteúdo faz parte das experiências vividas, conseguimos dar um significado e uma utilidade para aquela aprendizagem. Pois o ser humano só aprende por prazer ou necessidade". 
Nesse sentido, Lara enfatiza que:

[...] ao dar credibilidade ao aluno acreditando que os saberes matemáticos podem ser constituídos de modos diferentes, levando em conta que uma bagagem de conhecimento matemático sempre existe, o professor poderá aumentar a confiança desse aluno, obtendo como efeito um melhor desempenho (2004, p. 146).

A proposta de ensino destacada por Lara (2004) está presente no enunciado do Professor 1: "[...] o aluno para aprender precisa ter significado para ele. Assim, quando ele consegue fazer a relação do que está sendo estudado com suas vivências ele vai ter mais significado".

Em suas respostas, os participantes da pesquisa afirmaram que é possível as DA serem minimizadas, desde que o ensino da Matemática seja significativo e que vá ao encontro da contextualização da linguagem matemática na realidade dos estudantes, pois a aprendizagem, segundo os docentes, ocorre quando há prazer e necessidade de aprender.

\section{Resolução de problemas e jogos}

$\mathrm{Na}$ categoria resolução de problemas e jogos (4), os sujeitos salientam que o ensino deve ser contextualizado, priorizando a resolução de problemas, os jogos e 0 uso de materiais concretos, principalmente na educação infantil e nos anos iniciais.

Em relação à resolução de problemas, Lara menciona que:

O desenvolvimento do raciocínio lógico, da criatividade e do pensamento independente, bem como a capacidade de resolver problemas, só é possível através do ensino da Matemática, se nos propusermos a realizar um trabalho que vá ao encontro da realidade do nosso aluno onde seja possível, através de diferentes recursos, propiciarmos um ambiente de construção do conhecimento (2005, p. 15).

As ideias trazidas por Lara (2005) vão ao encontro da resposta do Professor 3: “[...] por meio de resolução de problemas e ou jogos matemáticos, etc.”.

O papel do lúdico é destacado por Chamat (2008) em relação à importância do jogo como instrumento fundamental para o trabalho com conflitos, ansiedades, medos, o ganhar ou perder, questões presentes no processo de aprendizagem. As ideias destacadas pela autora são salientadas pelo Professor 3: "[...] a utilização dos jogos matemáticos, propicia não apenas o trabalho com as questões da aprendizagem, mas também os conflitos emocionais, os quais influenciam na aprendizagem de nossos alunos".

Referente ao jogo, Bossa (2005) menciona que a maneira como a criança se posiciona no decorrer do jogo possibilita a compreensão de sua personalidade e a forma como está se relacionando com o mundo que o cerca, as suas angústias e as culpas acarretadas no ganhar e no perder. Isso é perceptível na resposta do Professor 8: 
Também, orientamos as famílias a proporcionarem aos seus filhos atividades, jogos e brincadeiras, como uma forma de ajudar nas questões das angústias que muitos alunos passam pelo medo do fracasso escolar.

Smole, Diniz e Cândido salientam que:

[...] o uso de jogos implica uma mudança significativa nos processos de ensino e aprendizagem que permite alterar o modelo tradicional de ensino [...] $\mathrm{O}$ trabalho com jogos [...] auxilia o desenvolvimento de habilidades como observação, análise, levantamento de hipóteses, busca de suposições, reflexão, tomada de decisão, argumentação e organização, que estão estreitamente relacionadas ao chamado raciocínio lógico (2007, p. 11).

A resposta dada pelo Professor 11 corrobora as ideias das autoras quando menciona que: "[...] é necessário (para crianças de Ed. Infantil e Séries Iniciais) aliar a realidade com o material concreto para que essa possa ser percebida de uma forma mais clara".

Assim, os participantes da pesquisa acreditam que é possível minimizar as dificuldades se o ensino da Matemática priorizar a contextualização, por meio da resolução de problemas e do uso de materiais pedagógicos, propiciando vivenciar na prática as questões teóricas, facilitando a aprendizagem e o gosto em aprender situações atreladas ao cotidiano.

Referente à análise das duas categorias, verifica-se que os participantes da pesquisa, por um lado, enfatizam que as DA podem ser minimizadas se o ensino da Matemática for significativo, partindo da contextualização da linguagem matemática na realidade dos estudantes, enfatizando um ensino que tenha como ponto de partida a bagagem cultural do aluno para, posteriormente, introduzir os conteúdos matemáticos, e, por outro, enfatizam a necessidade da contextualização, ressaltando a importância de o ensino da Matemática priorizar a resolução de problemas, os jogos e o uso dos materiais concretos como instrumentos possíveis na minimização das DA, facilitando, assim, a aprendizagem.

\section{Considerações finais}

Este artigo teve como objetivo apresentar uma análise da possibilidade de as DA serem minimizadas por meio da utilização da realidade do estudante no ensino de Matemática. Buscou identificar as percepções dos docentes participantes do estudo acerca da importância da valorização da realidade dos estudantes no processo de aprendizagem, por meio da análise das respostas dadas à questão central de pesquisa: De que modo abordar a realidade dos estudantes pode minimizar as dificuldades de aprendizagem em Matemática? Ao utilizar a ATD para trabalhar com tais respostas, surgiram algumas categorias de análise, as quais permitem apontar as considerações finais para cada um dos casos em específico. 
Em relação à percepção dos docentes acerca da Matemática, percebeu-se que a disciplina é tida como parte do cotidiano e como essencial no dia a dia, pois se faz presente em tudo o que fazemos, permitindo a compreensão do mundo. Além disso, a Matemática é definida como a ciência do raciocínio lógico, da resolução de problemas e dos números, possibilitando aos estudantes o pensamento crítico e a reflexão.

Em relação à percepção de realidade, em sua maioria, os professores pesquisados demonstraram que definem realidade como sendo a aproximação entre as vivências relacionadas ao mundo e a aprendizagem e sua importância no ensino da Matemática, pois somente dessa maneira será possível um ensino que priorize a realidade dos estudantes, realidade essa que está em constante transformação. Identificou-se que um dos participantes pesquisados definiu realidade como sendo a sua realidade vivenciada em sala de aula, a qual, segundo ele, é permeada de dificuldades enfrentadas pelos estudantes e da falta de apoio dos pais em auxiliar os filhos num trabalho em conjunto com a escola.

Quanto à percepção dos docentes no que se refere às DAM, percebeu-se que, para muitos participantes, elas estão relacionadas à falta de pré-requisitos e ao modo como o professor transmite os conteúdos, isto é, a linguagem matemática que é utilizada para ensinar, o que acaba ocasionando desinteresse dos estudantes e até mesmo aversão à disciplina. Além disso, outros participantes mencionaram que a visão dos estudantes sobre a Matemática, o desinteresse, o medo do fracasso e também as dificuldades cognitivas e/ou neurológicas são os responsáveis pelas DAM.

No que tange à percepção dos docentes a respeito de que abordar a realidade dos estudantes pode minimizar as DAM, observou-se com base na pesquisa realizada que os participantes enfatizam que as DA podem ser minimizadas se 0 ensino da Matemática for significativo, partindo da contextualização da linguagem matemática na realidade dos estudantes, enfatizando um ensino que tenha como ponto de partida a bagagem cultural para posteriormente introduzir os conteúdos matemáticos. Além disso, os participantes também mencionaram a necessidade da contextualização e ressaltaram a importância de o ensino da Matemática priorizar a resolução de problemas, os jogos e o uso dos materiais concretos como instrumentos possíveis na minimização das DA, de modo a facilitar a aprendizagem.

Concluindo, acredita-se ser considerável ampliar as pesquisas referentes a esse tema devido ao seu grau de importância para identificar algumas medidas que poderiam ser adotadas para minimizar as dificuldades de aprendizagem dos estudantes com a aproximação da Matemática à realidade.

\section{Nota}

1 O numeral entre parênteses representa a quantidade de enunciados agrupados na categoria. 


\section{Referências}

BOSSA, Nádia Aparecida. Introdução: avaliação psicopedagógica da criança de 7 a 11 anos. In: BOSSA, Nádia Aparecida; OLIVEIRA, Vera Barros (Org.). Avaliação psicopedagógica da criança de sete a onze anos. Petrópolis: Vozes, 2005. p. 7-14.

CHAMAT, Leila Sara José. Técnicas de intervenção psicopedagógica: para dificuldades e problemas de aprendizagem. São Paulo: Vetor, 2008.

FERNÁNDEZ, Alicia. O saber em jogo. Porto Alegre: Artes Médicas, 2001.

FINI, Maria Inês. Sobre a pesquisa qualitativa em educação, que tem a fenomenologia como suporte. In: BICUDO, Maria Aparecida Viggiani; ESPÓSITO, Vitória Helena Cunha (Org.). Pesquisa qualitativa em educação: um enfoque fenomenológico. 2. ed. São Paulo: Unimep, 1997. p. 23-34.

GARCÍA, Jesus Nicasio. Manual de dificuldades de aprendizagem: linguagem, leitura, escrita e matemática. Porto Alegre: Artes Médicas, 1998.

GIL, Antonio Carlos. Como elaborar projetos de pesquisa. 4. ed. São Paulo: Atlas, 2002.

LARA, Isabel Cristina Machado. Ensino inadequado de Matemática. Revista Ciências e Letras, Porto Alegre, n. 35, p. 137-152, mar./jul. 2004.

. Jogando com a Matemática na Educação Infantil e séries iniciais. São Paulo: Editora Rêspel, 2005.

MACHADO, Ozeneide Venâncio de Mello. Pesquisa qualitativa: Modalidade fenômeno situado. In: BICUDO, Maria Aparecida Viggiani; ESPÓSITO, Vitória Helena Cunha (Org.). Pesquisa qualitativa em educação: um enfoque fenomenológico. São Paulo: Unimep, 1997. p. 35-46.

MACHADO, Nílson José. Matemática e realidade. São Paulo: Cortez, 1997.

MORAES, Roque; GALIAZZI, Maria do Carmo. Análise textual discursiva. 2. ed. rev. Ijuí: Unijuí, 2011.

OHLWEILER, L. Introdução. In: ROTTA, N. T.; OHLWEILER, L.; RIESCO, R. S. (Org.). Transtornos da aprendizagem: abordagem neurobiológica e multidisciplinar. São Paulo: Artes Médicas, 2006. p. 127-130.

RELVAS, M. P. Neurociências e transtornos de aprendizagem: as múltiplas eficiências para uma Educação Inclusiva. Rio de Janeiro: Wak ED., 2015.

ROTTA, Newra. Dificuldades para a aprendizagem. In: ROTTA, Newra; OHLWEILER, Lygia; RIESCO, Rudimar (Org.). Transtornos da aprendizagem: abordagem neurobiológica e multidisciplinar. São Paulo: Artes Médicas, 2006. p. 113-123.

SMOLE, Kátia Stocco; DINIZ, Maria Ignez; CÂNDIDO, Patrícia. Cadernos do Mathema: matemática de $1^{\circ}$ a $5^{\circ}$ ano. Porto Alegre: Artes Médicas, 2007. 